\title{
Evaluation of Asbestos Exposure during Brake Repair and Replacement
}

\author{
Hossein KAKOOEI $^{1 *}$, Maryam HORMOZY ${ }^{1}$ and Hossein MARIORYAD ${ }^{1}$ \\ ${ }^{1}$ Deapartment of Occupational Health, School of Public Health, Tehran University of Medical Sciences, \\ Tehran 14155-6446, Iran
}

Received June 29, 2009 and accepted October 28, 2010

Published online in J-STAGE March 1, 2011

\begin{abstract}
Occupational exposure to asbestos fiber of brake repair job (auto mechanics) has seldom been evaluated in Iran. Accordingly, we evaluated asbestos fiber concentrations in the breathing zone of auto mechanics between July 2008 and December 2008. The asbestos fiber concentrations of 60 personal air samples collected from 30 cars and trucks brake replacement and they were analyzed by phase-contrast optical microscopy (PCM) and scanning electron microscopy (SEM) by energy-dispersive X-ray analysis. The geometric means of the personal monitoring fiber concentrations were $0.92 \mathrm{PCM} \mathrm{f} / \mathrm{ml}$ and $0.46 \mathrm{PCM} \mathrm{f} / \mathrm{ml}$ respectively in car and passenger heavy truck auto shops. There was a significant differences in the asbestos fiber concentrations between the car and truck auto shops $(p=0.006)$. Based on these findings, auto mechanics who worked with asbestos containing brake may have been exposed to asbestos concentrations approximately 7 times higher than the current occupational safety and health agency (OSHA) permissible exposure limit (PEL) of $0.1 \mathrm{f} / \mathrm{ml}$. Fiber morphology and energy dispersive $\mathrm{X}$-ray analysis by SEM revealed that amphibole fibers such as tremolite and actinolite existed in the brakes dust and that the vast majority ( $>30 \%)$ of the airborne chrysotile fibers were greater than $1 \mu \mathrm{m}$ in diameter. It can be concluded that the imported chrysotile asbestos contains trace amounts of tremolite and actinolite fibers and they are responsible for the high airborne asbestos levels and occupational exposure to amphibole asbestos in auto mechanics job in Iran. Thus, it is to be expected that the auto mechanics will suffer negative health effects due to exposure to the serpentine and amphibole asbestos fibers.
\end{abstract}

Key words: Airborne asbestos, Auto mechanic, Brake repair, Amphibole asbestos exposure, Iran

\section{Introduction}

Most motor vehicles, from passenger cars to heavy duty trucks, have disc brakes on the front wheels and drum brakes on the rear wheels which help control their movement. Asbestos containing brake lining are generally found in cars, light and heavy-duty trucks. Motor vehicle brakes typically require repairment or replacement every $24,000 \mathrm{~km}^{1)}$. Asbestos fibers specially type of chrysotile was a primary component of friction materials in car and truck brakes from early 1900s to the $1980 \mathrm{~s}^{2,3)}$. The chrysotile asbestos contents of the

*To whom correspondence should be addressed.

E-mail: hkakooei@sina.tums.ac.ir brake lining usually ranged from $35 \%$ to $65 \% 4)$. It was not until the 1960s, however, that concerns arose regarding the potential health hazard associated with occupational exposure to asbestos resulting from motor vehicles brakes ${ }^{5}$. The use of asbestos in Iran began in the 1950s, and by the mid-1970s it was being widely used in brakes and clutches ${ }^{6,7)}$. The use of chrysotile asbestos in industrial applications in Iran has not been declined. The imported amount of chrysotile for 2007 has been estimated 55,000 tons ${ }^{6,7)}$. In 2008, also 2000 tons of the chrysotile asbestos were used for manufacturing brake lining and clutch facing 7 ). The motor vehicles test methods, tools and conditions were as commonly used during the 1960s. The auto mechanic was experienced in brake repair, having worked in 
the automobile maintenance profession beginning in the $1960 \mathrm{~s}^{8}$. Vehicle mechanics may be exposed to airborne asbestos fibers when removing and replacing brake lining and pads. Several previous studies indicated that, brakes and brake components have been the primary source interest of the asbestos-containing materials in motor vehicles ${ }^{9,10)}$. According to previous reports, the incidence of lung cancer and mesothelioma in auto mechanics is significantly higher than in the general population ${ }^{11,12)}$. It has been known for decades that, during brake lining maintenance and repair, the average asbestos concentrations were very high ${ }^{13}, 14$. Specifically, in 1976, Rohl et al. reported that auto mechanics may have been exposed to concentrations of airborne asbestos approximately 373 times higher than the current Occupational Safety and Health Agency (OSHA) permissible exposure limit (PEL) of $0.1 \mathrm{f} / \mathrm{cc}^{13}$ ). Other reported measurements of asbestos fibers during the grinding of a new lining, before installation, were 2.7 and 4.8 fibers $/ \mathrm{cc}^{14)}$. Numerous studies have shown that the time-weighted average (TWA) airborne asbestos levels during brake lining repair or replacement on cars and trucks are consistently higher than the current OSHA PEL of $0.1 \mathrm{f} / \mathrm{cc}^{15}, 16$ ). In 1971 , the OSHA modified its permissible exposure limit (PEL) to eliminate the development of asbestosis, in which the 8-h concentration limits for occupational environment asbestos fiber were 12 fiber per milliliter (12 f/ml). In 1994 the standard had been lowered to the current standard of $0.1 \mathrm{f} / \mathrm{ml}$, mainly to reduce the risk of asbestos-related cancer ${ }^{17)}$. Although there have been three reports of airborne asbestos concentrations in a brake lining manufacturing plant and in a urban area of Tehran ${ }^{5-7)}$, there have been no reports of asbestos at exposure levels in brake repair process. Given this lack of data on fiber exposure in the auto mechanics job and the background of approximately $50 \mathrm{yr}$ of asbestos use in Iran, an evaluation of workplace asbestos exposure is needed. These data are needed for the planning of a national program regarding banning the use of asbestos. Aims of this study were: (1) to determine airborne asbestos fiber concentrations by PCM in the brake repair and replacement job in a developing country; and (2) to compare the elemental compositions of asbestos for determining airborne asbestos types by SEM.

\section{Materials and Methods}

\section{Process description}

This study was conducted in 30 brake repair and replacement auto shops (cars and trucks) in Zahedan city that located in the south-east of Iran. They currently employ 75 (45 workers and 30 auto mechanics)

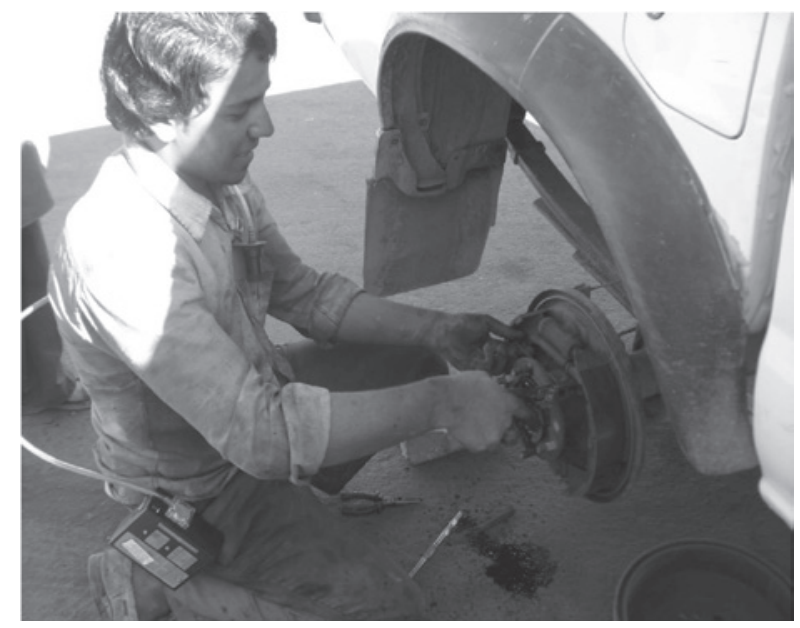

Fig. 1. A brake repair worker at work.

and repair 3,750 cars and trucks monthly. The number of workers and auto mechanics per auto shops were approximately 2-3 person (1-2 worker and 1 auto mechanic). The mean age (range) of workers were 29 (18-40) yr. The mean employment period (range) of the workers were $11.5(2-25)$ yr. In these auto shops brake replacement is a common job that auto mechanics perform them. The main processes carried out during brake repair and replacement are remove wheel and drum, clean and remove brake parts and install brakes and drum. In the brake repair processes, accumulated brake dust must be cleaned away before the old pads and linings removed (Fig. 1). This is often done with a small brush under inadequate engineering controls such as local exhaust ventilation hoods. Either method may cause asbestos fibers to become airborne. If the old brake lining is still thick enough to be effective, the automotive mechanic may use a bench grinder to restore the surface, or deglaze the linings of oil and dirt.

\section{Sampling and analysis}

Personal air samples were collected between July 2008 and December 2008. Airborne asbestos was analyzed in 60 personal air samples collected in the auto shops (two personal samples in each auto shops). The samples were collected on mixed cellulose ester (MCE) filter membranes (Millipore type AA; $0.45 \mu \mathrm{m}$ pore size; $25 \mathrm{~mm}$ diameter) using an open-face filter holder and a cellulose support pad contained in a three piece cassette with a 50-mm conductive extension cowl. Sampling was performed at a flow rate of 1.7 liter per minute (LPM) using a personal sampling pump (model 224-PCX R3; SKC -West, Inc, Fullerton, CA,USA). The time weighted average (TWA) exposure can be calculated using the same equation as used for the assumption that the exposure in the unsampled period is the same 
as in the sampled period. The TWA airborne asbestos concentrations were calculated from the 45-min samples obtained from the breathing zone of the worker using the following equation:

$$
\mathrm{TWA}=\frac{\left(C_{1} \times T_{1}\right)+\left(C_{2} \times T_{2}\right)+\cdots+\left(C n \times T_{n}\right)}{T_{1}+T_{2}+\cdots+T_{n}}
$$

Where $C_{1}$ is the average airborne concentration $(\mathrm{f} / \mathrm{ml})$ for the breathing zone for each of the sampling segments and $t_{1}$ is the duration of the task.

Collection of all airborne asbestos samples was consistent with National Institute for Occupational Safety and Health (NIOSH) method $7400^{18)}$. In this method, the filter is first treated to make it transparent and then analyzed by Phase Contrast Microscopy (PCM) (magnification of 400-450 ×) using Walton-Bechette graticule (type G-22). A fiber was defined as any particle greater than $5 \mu \mathrm{m}$ in length and having at least a 3:1 aspect ratio. The analytical sensitivity was approximately $0.01 \mathrm{f} /$ $\mathrm{ml}$ of air sampled. Another portion of the $25 \mathrm{~mm}$ diameter filter was prepared and analyzed for the qualitative evaluation according to the SEM method (detection limit $0.4 \mathrm{f} / \mathrm{l}$ ) specified by the Asbestos International Association ${ }^{18)}$. The SEM (model XL30; Philips, Eindhoven, the Netherlands) was used in combination with energy-dispersive X-ray analysis (EDXA) to identify asbestos during the analysis of some of the samples. The SEM analysis usually images fibers equal or greater than $0.25 \mu \mathrm{m}$ in diameter because it has contrast limitations, while Transmission Electron Microscopy (TEM) can visualize fibers of all sizes ${ }^{19,21)}$.

\section{Fiber size and morphology}

Because OSHA specifies PCM measurement for the assessment of occupational exposure to airborne asbestos fibers, most workplace sampling and analysis of airborne asbestos utilize the NIOSH method $7400^{18)}$. Although, this method is relatively fast and inexpensive, it does not distinguish between fibers of asbestos and non-asbestos origins, and it can not detect fibers thinner than $0.25 \mu \mathrm{m}^{18,20)}$. While these analytical method (NIOSH 7400 and 7402) ${ }^{18,20)}$, are unable to assess the fiber size (length and width) of any given fiber, the International Organization for Standardization (ISO) ${ }^{21}$ ) and AIA ${ }^{19)}$ methods are a refined technique using SEM with energy-dispersive X-ray analysis (EDXA) that permits characterization of both fiber size and type. The AIA method is refined technique using SEM that permits to detect the smallest fibers than PCM and also fiber type by detection limit 0.4 fibers/liter.

\section{Data and statistical analysis}

Descriptive statistics were calculated for the PCM measurements of airborne fiber concentrations using the SPSS software for Windows. The mean fiber concentrations of the airborne samples between car and truck auto shops were compared by $t$-test. The TWA airborne asbestos concentrations were compared to the current OSHA PEL of $0.1 \mathrm{f} / \mathrm{ml}$.

\section{Results}

\section{Airborne asbestos sample analyses}

The geometric mean values of airborne asbestos in the samples collected from the 32 cars and the 28 trucks auto shops are given in Table 1. As summarized in Table 1, for automotive mechanics in car auto shops, fiber concentrations were significantly higher than the truck auto mechanics $(0.46 \mathrm{PCM} \mathrm{f} / \mathrm{ml})(p=0.006)$. As the results shows, the geometric mean personal asbestos fiber concentration was $0.67 \mathrm{PCM} \mathrm{f} / \mathrm{ml}$, which is considerably high (more than 7 fold) comparing to the PEL of $0.1 \mathrm{PCM} \mathrm{f} / \mathrm{ml}$ recommended for occupational exposure to asbestos by the OSHA ${ }^{16}$. Table 2 shows the airborne asbestos fiber concentrations in each of the two seasons. The geometric means of the asbestos fiber concentrations were significantly higher in the summer $(1.27 \mathrm{PCM} \mathrm{f} / \mathrm{ml})$ than in the autumn $(p<0.001)$.

\section{Fiber size and morphology}

Table 3 presents the number of asbestos by type and total fiber counting from 2,435 counted fibers by PCM and SEM. Fiber size and morphology were assessed for personal auto shops samples collected during brake repair and replacement activities. For the purpose of

Table 1. Airborne asbestos fiber concentrations by auto shops

\begin{tabular}{lccc}
\hline Auto shops & Number of sample & $\begin{array}{c}\text { Asbestos fiber concentrations (fiber/ml) } \\
\text { Mean (SD) }\end{array}$ & Range \\
\hline Cars & 32 & $0.92(2.52)^{*}$ & $0.116-2.48$ \\
Trucks & 28 & $0.46(2.57)$ & $0.117-1.93$ \\
\hline
\end{tabular}

$* p=0.006$, compared with the trucks auto shops.

${ }^{a}$ values are given as geometric mean, with the geometric standard deviation given in parenthesis. 
Table 2. Airborne asbestos fiber concentrations by seasons

\begin{tabular}{|c|c|c|c|c|}
\hline \multirow[t]{2}{*}{ Season } & \multicolumn{2}{|c|}{ Number of sample } & \multicolumn{2}{|c|}{ Asbestos fiber concentrations(fiber $/ \mathrm{ml})^{\mathrm{a}}$} \\
\hline & Cars & Trucks & Mean (SD) & Range \\
\hline Summer & 22 & 10 & $1.27(2.06)^{*}$ & $0.135-2.48$ \\
\hline Autumn & 10 & 18 & $0.29(1.77)$ & $0.116-1.62$ \\
\hline
\end{tabular}

$* p<0.001$, compared with autumn.

${ }^{\mathrm{a}}$ values are given as geometric mean, with the geometric standard deviation given in parenthesis.

Table 3. Number of asbestos by type and total fiber counting in auto shops

\begin{tabular}{|c|c|c|c|c|c|c|}
\hline \multirow{3}{*}{ Auto shape } & \multicolumn{3}{|c|}{ Chrysotile } & \multicolumn{3}{|c|}{ Tremolite/Actinolite } \\
\hline & \multirow{2}{*}{$\begin{array}{l}\text { Length }^{\mathrm{a}} \\
\text { (range) }\end{array}$} & \multicolumn{2}{|c|}{ Diameter $^{\mathrm{a}}$} & \multirow{2}{*}{$\begin{array}{l}\text { Length }^{\mathrm{a}} \\
\text { (range) }\end{array}$} & \multicolumn{2}{|c|}{ Diameter $^{\mathrm{a}}$} \\
\hline & & $<1$ & $>1$ & & $<1$ & $>1$ \\
\hline Cars & $5-30$ & 860 & 550 & $5-15$ & 210 & 360 \\
\hline Trucks & $5-15$ & 247 & 112 & $5-10$ & 14 & 82 \\
\hline Totals & $5-30$ & 1,107 & 662 & $5-15$ & 224 & 442 \\
\hline
\end{tabular}

${ }^{\mathrm{a}}$ values are given as $\mu m$.

this analysis, the limit of detection of fiber length was $5 \mu \mathrm{m}$. Fiber size and morphology analysis by SEM revealed that both serpentine (chrysotile) and amphibole fibers such as actinolite and tremolite were detected in the brakes dust and that the vast majority $(>30 \%)$ of the airborne chrysotile fibers were greater than $1 \mu \mathrm{m}$ in diameter (Table 3). Approximately half $(50 \%)$ of the fibers were of a respirable width (less than $1 \mu \mathrm{m}$ ). The elemental composition of the fibers was analyzed by energy dispersive spectrometry (EDS) analysis. The SEM image and EDS spectrum collected from the airborne chrysotile fiber in the workplace is shown in Figs. 3 and 5. This spectrum (Fig. 3) show the chemical analysis and a magnesium to silicon $(\mathrm{Mg} / \mathrm{Si})$ ratio of 1.29. When all the data and information are considered in personal samples and EDS spectrum the results indicated that the fibrous particles in the auto shops environment consisted of chrysotile $70 \%(\mathrm{n}=1,769)$, tremolite $10 \%(\mathrm{n}=334)$ and actinolite $10 \%(\mathrm{n}=332)$.

\section{Discussion}

Occupational exposure to asbestos fiber in brake repair job (auto mechanics) has rarely been evaluated in Iran. As noted earlier, automobile brake and clutch manufacturers have continued widespread use of chrysotile asbestos in Iran ${ }^{5,6)}$. As the results show the workers who work in car auto shops are exposed to the higher concentration of asbestos fibers $(0.92 \mathrm{PCM} \mathrm{f} / \mathrm{ml})$, while the truck auto shops workers have lower exposure $(0.46 \mathrm{PCM} \mathrm{f} / \mathrm{ml})$. This may be attributed in part to the fact that the current truck brake repair practices

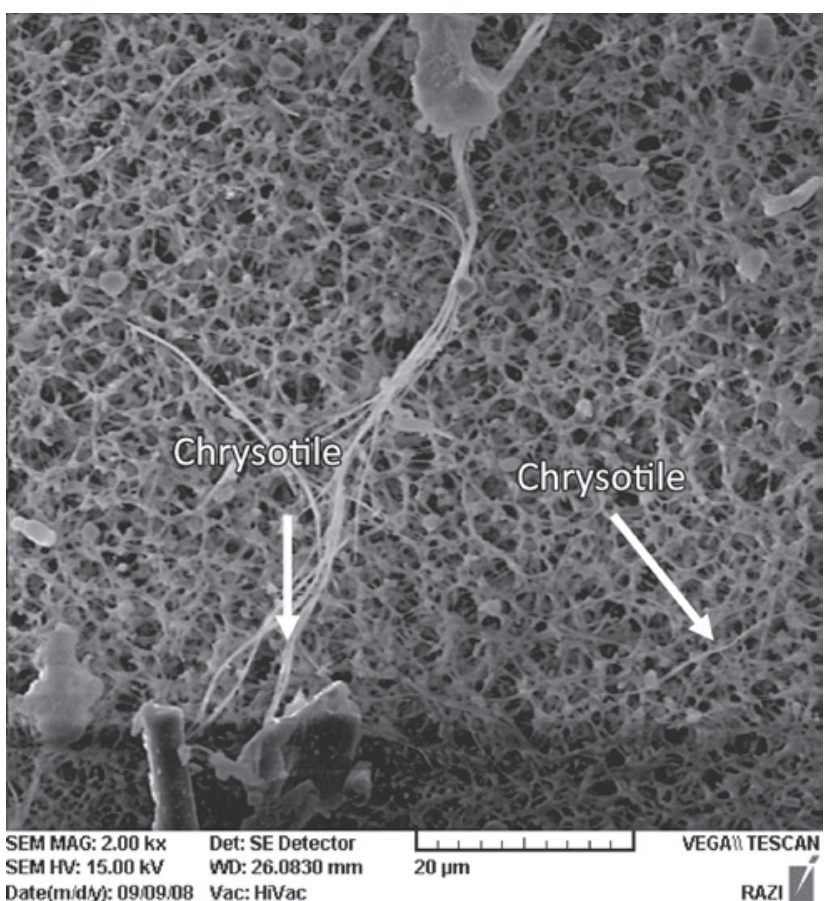

Fig. 2. SEM image collected from the air Chrysotile fiber.

the actual time spent blowing the dust was shorter (several seconds per wheel) than car brake repair and most car auto shops are relatively small than the truck auto shops. Previous studies of asbestos exposure among automotive mechanics predominantly report fiber levels at or below the current OSHA PEL ${ }^{8,13}, 15,16$ ). Blake et al., reported that airborne chrysotile fiber exposure for the vehicles test remained below currently applicable 


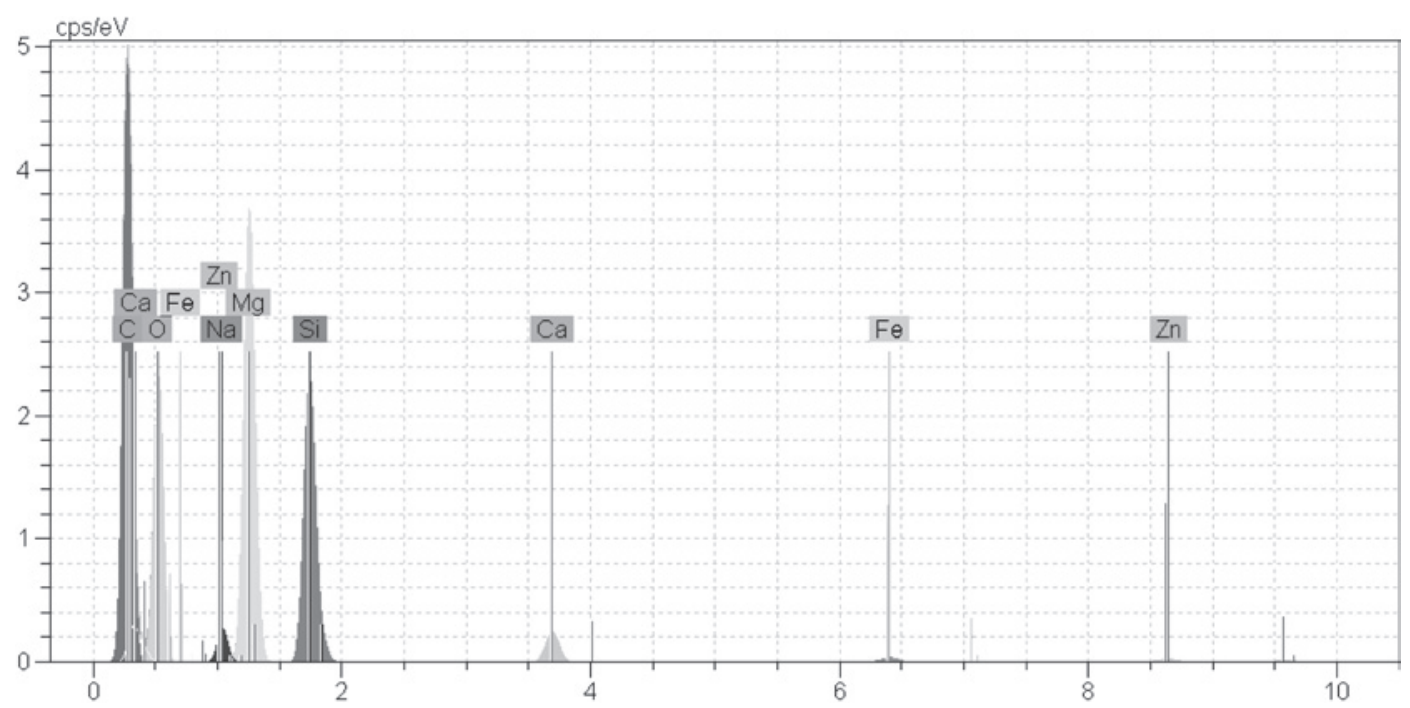

Fig. 3. EDS spectrum collected from the air chrysotile fiber.

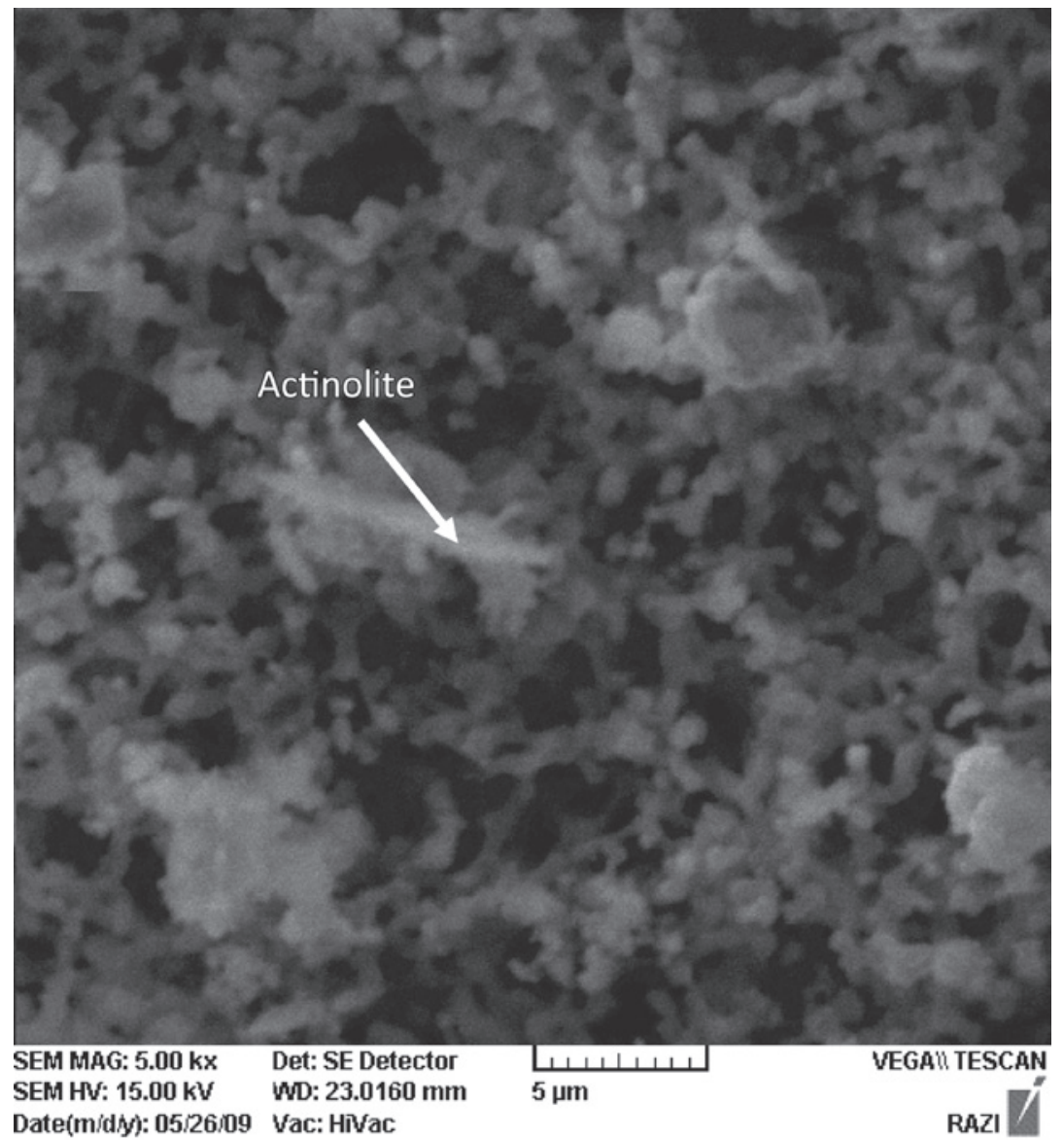

Fig. 4. SEM image collected from the air actinolite fiber.

limit of $0.1 \mathrm{f} / \mathrm{ml}^{8)}$. In a study of truck brake lining maintenance and repair, Rohl et al. indicated that the average asbestos concentration was $37.3 \mathrm{PCM} \mathrm{f} / \mathrm{cc}^{13}$. Cheng et al., conducted an exposure evaluation aimed at determining the asbestos fiber concentrations associated with the repair of brake pad ${ }^{15)}$. The mean PCM observed in personal samples was $0.55 \mathrm{f} / \mathrm{cc}^{15)}$. During the machine grinding of brake linings, Kauppinen et al. 


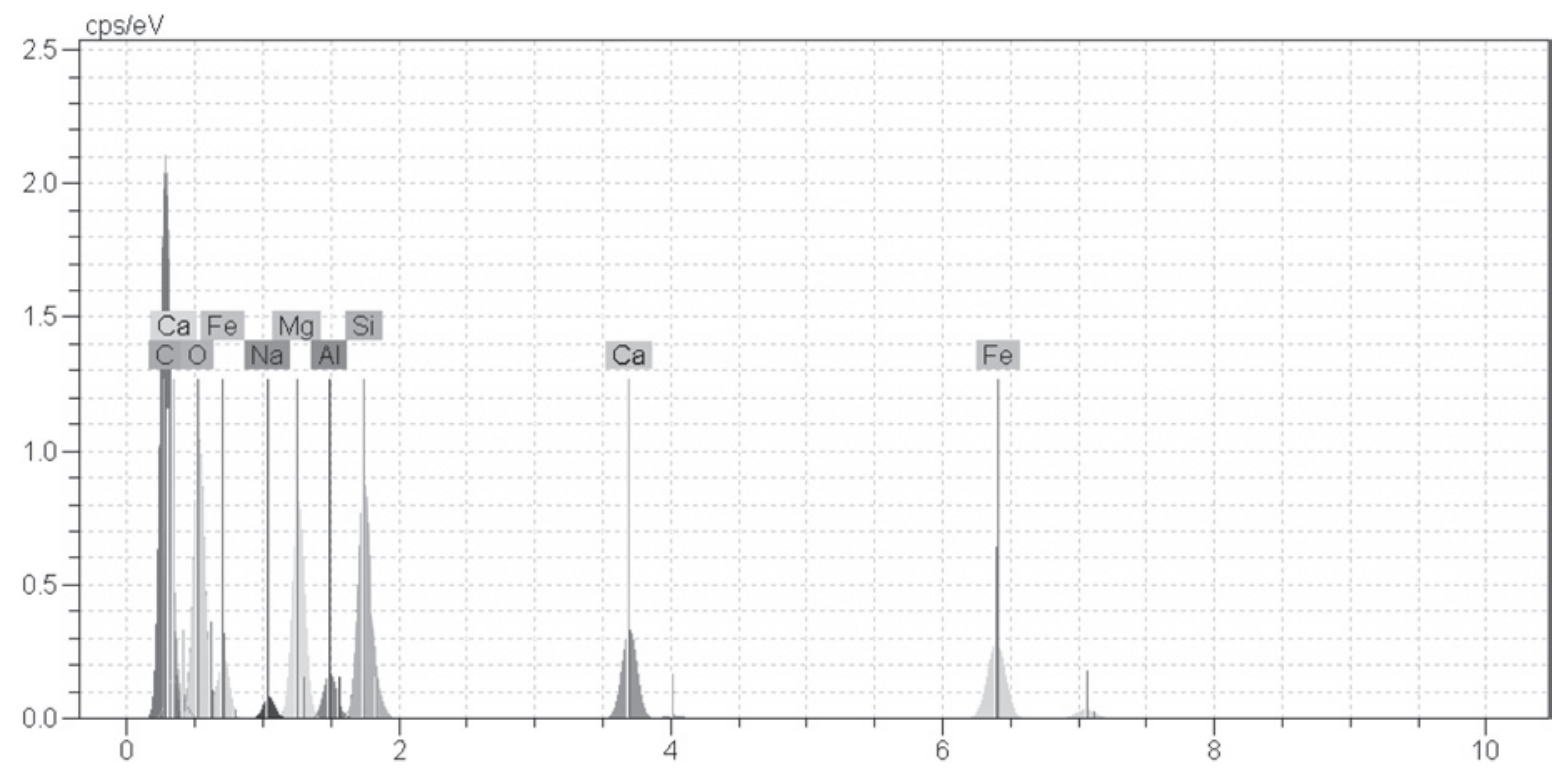

Fig. 5. EDS spectrum collected from the air actinolite.

also found a mean asbestos fibers concentration of 56 PCM f/cc ${ }^{16)}$. The results of the current study indicate that repair asbestos containing brake pads and linings on cars and trucks has produced significant airborne asbestos. It is interesting to note that the personal PCM results of an in few preceding studies have reported arithmetic mean instead of geometric mean ${ }^{16)}$. As it has been illustrated in the Table 2, the seasonal differences may be explained the more frequent presence of seasonal wind (about $14 \mathrm{~km} / \mathrm{h}$ ) during the summer. As mentioned above, all of the individual PCM concentrations exceeded than OSHA PEL of $0.1 \mathrm{f} / \mathrm{cc}$. The geometrical mean $(0.67 \mathrm{PCM} \mathrm{f} / \mathrm{ml})$ of the personal asbestos fiber concentrations of the auto shops, i.e., 7 times above than current OSHA PEL criteria. Congruent with many studies ${ }^{13}, 15,16$ ), this study confirm that auto mechanics have a higher asbestos exposure in the brake linings repair and replacement (Tables 1 and 2). In contrast, few previous studies $\left.{ }^{8,} 22\right)$, have reported that mean asbestos concentrations in the vehicular brake service were below currently applicable limit of $0.1 \mathrm{f} / \mathrm{ml}$, which are lower than those found in this study. The lower airborne asbestos levels in those studies could be attributed to a better regulation of asbestos-containing materials, such as brake linings and clutches. It has recently been recognized that the carcinogenicity of asbestos is strongly related to the fiber dimension ${ }^{22}$. Recently, the U.S. Environmental Protection Agency (EPA) technical report have concluded that asbestos fibers $<5 \mu \mathrm{m}$ in length or up to $20 \mu \mathrm{m}$ in length probably do not contribute to disease ${ }^{23)}$. The elemental composition of the fibers was analyzed by EDS analysis
(Figs. 3 and 5). Relative elemental concentrations can be estimated from the peak areas in the EDS analysis of the airborne asbestos ${ }^{6}$. As, in the example of the EDS spectrum of airborne chrysotile shown in Fig. 2 the magnesium to silica $(\mathrm{Mg} / \mathrm{Si})$ ratio is 1.29 . These data can be compared to the composition of standard reference chrysotile $(\mathrm{Mg} / \mathrm{Si} \text { ratio } 1.45)^{7)}$. It should be noted that chrysotile contain more magnesium oxide and silica $(>40 \%)$ but very little iron $(1 \%)$, while actinolite and tremolite contain only large amounts of silicon (51\% to $60 \%$ ). The serpentine asbestos (chrysotile) fibers are usually curved (Fig. 2), in contrast to the straight morphometry of amphiboles (Fig. 4). Although chrysotile asbestos were used to manufacture asbestoscontaining automobile brake linings in Iran, it has been known that the imported chrysotile asbestos contained trace amounts of actinolite and tremolite fibers ${ }^{7}$. As it is known, actinolite and tremolite asbestos are present in or around some deposite of chrysotile asbestos. Earlier studies on the type of amphibole asbestos in raw chrysotile asbestos have shown that asbestos-containing brakes had no detectable amphibole fibers; in comparison in the current study we found that some amounts of actinolite $(10 \%)$ and tremolite $(10 \%)$ present in the auto shops work place ${ }^{8)}$. As noted in Figs. 3 and 5, the airborne chrysotile contains $\mathrm{Mg}$ and $\mathrm{Si}$ and $\mathrm{MG} / \mathrm{Si}$ ratio is approximately 1.29 , while actinolite and tremolite contains calcium and the $\mathrm{Mg} / \mathrm{Si}$ ratio is 0.26 .

\section{References}

1) Gilles $T$ (2005) Automotive Chassis: Brakes, Steering 
\& Suspension, Thomson Delmar Learning. A Division of Thomson Learning, Inc, USA.

2) Sheehy JW, Cooper TC, D'Brien DM (1989) Control of asbestos exposure during brake drum services, National Institute for Occupational Safety and Health, Cincinnati.

3) Paustenbach DJ, Finley BL, Lu ET, Brorby GP, Sheehan PJ (2004) Environmental and occupational health hazards associated with the presence of asbestos in brake linings and pads (1900 to present): a state -of-the-art review. J Toxicol Environ Health 7, 25-80.

4) Anderson AE, Gealer RL, McCune RC (1973) Asbestos emissions from brake dynamometer test. Ford Motor Company Scientific Research Staff, MI Technical Report No. SR, 64-73.

5) Kakooei H, Sameti M, Kakooei AA (2007) Asbestos exposure during routine brake lining manufacture. Ind Health 45, 787-92.

6) Kakooei H, Yunesian M, Marioryad H, Azam K (2009) Assessment of airborne asbestos fiber concentrations in urban area of Tehran, Iran. Air Qual Atmos Health 2, 39-45.

7) Kakooei H, Marioryad H (2010) Evaluation of exposure to the airborne asbestos in an automobile brake and clutch manufacturing industry in Iran. Regul Toxico Pharmaco 56, 143-7.

8) Blake CL, Van Orden DR, Banasik M, Habison RD (2003) Airborne asbestos concentration from brake changing does not exceed permissible exposure limit. Regul Toxico Pharmaco 38, 58-70.

9) Dement JM, Kuempel ED, Zumwalde RD, Smit RJ, Stayner LT, Loomis D (2008) Development of a fiber size-specific job-exposure matrix for airborne asbestos fibers. Occup Environ Med 65, 605-12.

10) Richter RO, Finley BL, Paustenbach DJ, Williams PR, Sheehan PJ (2008) An evaluation of short-term exposure of brake mechanics to asbestos during automotive and truck brake cleaning and machining activities. J Expo Sci Environ Epidemiol 10, 36-43.

11) Langer AM, McCaughey WTE (1982) Mesothelioma in a brake repair worker. Lancet 8307, 1101-3.

12) Levin JL, O Sullivan MF, Corn CJ, Williams MG, Dodson RF (1999) Asbestos and small cell lung can- cer in a clutch prefabricator. J Occup Environ Med 56, 602-5.

13) Rohl AN, Langer AM, Wolff MS, Weisman I (1976) Asbestos exposure during brake lining maintenance and repair. Environ Res 12, 110-28.

14) Lorimer WV, Rohl AN, Miller A, Nicholson WJ, Selikoff IJ (1976) Asbestos exposure of brake repair workers in the United States. Mt Sinai J Med 43, 207-18.

15) Cheng VKI, O Kelly FJ (1986) Asbestos exposure in the motor vehicle repair and servicing industry in Hong Kong. J Soc Occup Med 36, 104-6.

16) Kauppinen T, Korhonen K (1987) Exposure to asbestos during brake maintenance of automotive vehicles by different methods. Am Ind Hyg Assoc J 48, 499-504.

17) American Conference of Industrial Hygienists (2008) Threshold limit values for chemical substances. ACGIH, Cincinnati.

18) National Institute for Occupational Safety and Health (1989) Method 7400: Fibers. In: NIOSH manual of analytical method, 3th Ed., U.S. Department of Health, Education and Welfare, Cincinnati.

19) Asbestos International Association (1984) Method for the determination of airborne asbestos fibers and other inorganic fibers by scanning electron microscopy. AIA Health and Safety Publ RTM no2. AIA, London.

20) National Institute for Occupational Safety and Health (1994b) Asbestos by TEM. In: Manual of analytical methods, 4th Ed., U.S. Department of Health and Human Services, NIOSH, Cincinnati.

21) ISO (1995) Ambient Air-Determination of Asbestos Fibers-Direct-Transfer Transmission Electron Microscopy Method. International Organization for Standardization, Geneva.

22) Berman DW, Crump KS (2008) A meta-analysis of asbestos-related cancer risk that address fiber size and mineral type. Crit Rev Toxicol 6, 49-73.

23) US Environmental Protection Agency (2003) Final draft: technical support document for a protocol to assess asbestos-related risk. USEPA. Prepared for the Office of Solid Waste and Emergency Response, Washington, DC. 